\title{
Dandy-Walker Malformation
}

National Cancer Institute

\section{Source}

National Cancer Institute. Dandy-Walker Malformation. NCI Thesaurus. Code C75012.

A rare congenital brain malformation disorder characterized by agenesis or hypoplasia of the cerebellar vermis, cystic dilatation of the fourth ventricle, and enlargement of the posterior fossa. 